\title{
Requiem for a Dream: Perceived Economic Conditions and Subjective Well-Being in Times of Prosperity and Economic Crisis
}

\section{Roger Fernandez-Urbano ${ }^{1}$ (D) . Nevena Kulic ${ }^{2}$}

Accepted: 1 June 2020 / Published online: 8 June 2020

(c) Springer Nature B.V. 2020

\begin{abstract}
Using the Panel of Social Inequalities in Catalonia, Spain (PaD 2001-2012), this article investigates the relationship between perceptions of economic conditions and subjective well-being in times of prosperity and economic crisis. It also analyses how this relationship plays out across different social backgrounds. Periods of economic crisis and prosperity serve as a proxy for objective macroeconomic conditions. The Spanish region of Catalonia is a relevant setting because it faced one of the highest increases in inequality and unemployment in Europe as a result of the 2008 Economic Crisis. Our results show that perceived economic conditions matter beyond objective micro and macroeconomic realm and become a strong determinant of subjective well-being during a crisis, particularly for the middle class. However, contrary to our initial expectations, our results also show the existence of a close correlation between perceptions of economic conditions and subjective well-being for low social background individuals in times of economic prosperity, and an even stronger relationship in times of economic crisis. The article stipulates several potential explanations for these results.
\end{abstract}

Keywords Subjective well-being $\cdot$ Perceptions $\cdot$ Social background $\cdot$ Economic crisis · Spain

\section{Introduction}

Individual subjective well-being is thought to be largely influenced by objective material conditions such as income and employment (Andersen 2008; Strandh 2001). Given that income in economic and philosophical theory is seen as an important means of autonomy,

Roger Fernandez-Urbano

roger.fernandez-urbano@eui.eu

$\triangle$ Nevena Kulic

nevena.kulic@uni-konstanz.de

1 Department of Political and Social Sciences, European University Institute, Via dei Roccettini, 9, 50014 San Domenico di Fiesole, Florence, Italy

2 Cluster of Excellence "The Politics of Inequality", University of Konstanz, Universitaetsstrasse 10, 78464 Constance, Germany 
there is abundant literature on the extent to which individual income may improve individual subjective well-being (Layard 2010; Sen 2009). While positive returns due to a growing income are documented, a study by Easterlin (1974) revealed that subjective well-being only increases with increasing income up to a certain point, after which it stabilizes and even starts to decrease. This is known as the 'Easterlin Paradox', and it motivated consequential research on the phenomenon (i.e. within the well-known economics of happiness literature). While income is expressed numerically and people are asked to report it factually without endowing it with personal characteristics, this can sometimes narrow the real picture of the well-being of an individual. Instead, subjective indicators of economic conditions measure attitudes and can also be important in true assessments of well-being (Van Praag et al. 2003); neglect for how people feel about their economic situation may bias the overall conclusions.

In this paper, we rely on a want-based approach while seeking to explore the distinction between needs, which represent an objective evaluation, and wants, as subjective measures of what people perceive (Allardt 1993). We delve into this by studying a rather unexplored dimension of perceptions of economic conditions in relation to subjective well-being after accounting for individual objective conditions like income or labour market situation. Specifically, we ask the following: How are perceptions of economic conditions related to subjective well-being, and do they matter beyond objective individual conditions? If yes, do these perceptions matter more within specific macroeconomic conditions and for specific groups as designated by social background?

Subjective well-being in our study is defined as life satisfaction. We apply our research questions to a case study of Catalonia, Spain, in the period from 2002 to 2012 when the region and the country shifted from prosperity to recession. Catalonia is a region in Spain with one of the highest reported levels of subjective well-being while Spain is in the top $20 \%$ of the happiest countries in the world (World Happiness Report 2019). Catalonia is an example of a relatively well-off region with a stable social structure that nonetheless faced extremely volatile economic conditions during the 2008 Economic Crisis, allowing for an examination of the role of perceived economic situation on individual subjective wellbeing in different periods of time. Furthermore, Catalonia hosts one of the few longitudinal surveys in Southern Europe and the only one available in Spain, the so-called 'Panel of Social Inequalities in Catalonia' (PaD).

Our contribution to the literature is manifold. First, there has been work on subjective well-being connected to three interrelated concepts relevant to our research: economic risk, economic uncertainty and perceptions of economic conditions-also defined as consumer confidence. Although the three concepts might seem similar, they refer to distinct psychological constructs. Economic risk applies to a situation in which statistical probabilities are recognized based on known chances, while (economic) uncertainty equates to situations in which statistical probabilities cannot be determined because chances are unknown (Runde 1998: 543; Knight 1921). Perceptions of economic conditions (or consumer confidence) instead can broadly be defined as public views of economic conditions (Merkle et al. 2003). In other words, while economic uncertainty refers to the variance of the distribution, consumer confidence illustrates the mean of the distribution. In our analysis, we explore perceived economic conditions due to its relevance as an economic and social indicator (Jansen and Nahuis 2003; Fisher and Statman 2000), and we analyse its relationship with individual subjective well-being.

Second, the study further examines how this relationship was affected by the 2008 Economic Crisis. Stiglitz et al. (2018) claim that, even if in 2010 there had been a substantial GDP increase in the Organisation for Economic Co-operation and Development (OECD) 
countries, the majority of people world would still have felt they were in a recession. In other words, individual perceptions of the economic situation impacted subjective wellbeing even if the economic situation objectively improved. Consequently, if politicians had taken perceptions of economic situation metrics into consideration when assessing the impact of the 2008 Great Recession, they could have seen that its consequences were much more significant than the official statistics indicated. The existing literature, though limited, finds that perceptions of economic conditions indeed matter for subjective well-being beyond income, particularly in times of economic downturn (Tonzer 2017; Giugni and Mexi 2018). In this article, we focus on the 2008 Economic Crisis as a particularly clear example of an economic downturn.

Third, our study investigates how this relationship played out across different social backgrounds. Individuals of the same social background tend to be socialized similarly and operate in closed social circles (Fiske and Markus 2012), which influences self-perception and future expectations about individual positions (Bandura 1999). Moreover, researchers have found that individuals from the middle social class might be more affected by an economic crisis than low and high social class individuals (Kiess and Lahusen 2018). In this article, we address whether individuals from different social backgrounds in Catalonia, Spain have different coping mechanisms overall and in times of economic crisis.

Finally, previous research on perceived economic situations and subjective well-being has predominantly used cross-sectional data. Taking into consideration that perceived economic situation and subjective well-being are psychological constructs influenced by socioeconomic factors, individuals' unobserved heterogeneous fixed effects can play an important role when drawing conclusions. Our study addresses this limitation by using the only available Spanish longitudinal-panel data $(\mathrm{PaD})$.

We begin by describing the theoretical and empirical research that focuses on the relationship between perceived economic conditions and subjective well-being in times of economic crisis and prosperity, as well as the role of social background in it. These sections ground and define our hypotheses. Subsequently, the selected case study is presented, as well as a description of the data, the methodology and our empirical model. We then lay out our findings, and the final section concludes.

\section{Theoretical Discussion and Hypotheses}

\subsection{Perceptions of Economic Conditions and Subjective Well-Being}

Perceptions of economic conditions are operationalized by asking individuals questions as to their perceptions of the future evolution of their household economic situation and the economy as a whole (Hacker 2018). Similar to the concepts of risk and uncertainty, it contains two main subjective dimensions: a microeconomic sentiment (referring to each respondent's economic situation in terms of the household) and a macroeconomic sentiment (referring to the evolution of the national economy) (Borra and Gómez-García 2016; Luechinger et al. 2010). Although the literature is light on the direct relationship between perceptions of economic conditions and subjective well-being, the two concepts can be closely related. Some studies suggest that perceived economic conditions can influence subjective well-being both at the aggregate national level (Merkle et al. 2003) as well as at the individual level by altering individuals' propensity to make decisions and take risks (Stiglitz et al. 2018). Otis (2017) provided evidence of the strong relationship between 
perceived economic circumstances and subjective well-being beyond objective factors within rural and urban China. Similarly, in a panel study focused on the microeconomic sentiment of perceptions of economic conditions in the UK, Oskrochi et al. (2018) argued that one of the most important variables affecting subjective well-being is the perception of one's future financial situation. Relating this to public policy, Campara et al. (2017) found that, even if small governmental cash transfers generally increased subjective well-being for poor Brazilian families, this was not sufficient to eliminate individuals' general negative perceptions of their household's economic situation. Other studies that examined individuals' perceptions of their household finances also uncovered a positive relationship with specific facets of subjective well-being like self-esteem (Krause et al. 1991) or low levels of depression (Rocha and Strand 2004). These claims build on Bovi (2009), who stated that consumer confidence illustrates information about feelings, as it reflects the moods of citizens and frequently contains heuristic and biased responses.

Other far more extensive research on variables closely related to perceptions of economic conditions also points to a relationship with subjective well-being. An example of this is research on subjective job insecurity, defined as one's feelings about a possible job loss in the near future (Chung and Mau 2014). Research has found a relationship both significant and negative between job insecurity and subjective well-being and that an individual's perception of job insecurity matter for subjective well-being beyond their objective situation (Geishecker 2012; Knabe and Rätzel 2011). Green (2011) also found that the effects of extreme job insecurity on subjective well-being parallel those of unemployment. Moreover, other studies have discussed how job insecurity appears to have more lasting adverse psychological effects than long-term unemployment (Burchell 2011). The individual expectation of finding new employment when wanted or needed is a related concept (Berntson and Marklund 2007). Different studies have uncovered a rather positive relationship between positive expectations of finding new employment and individual subjective well-being (Karren and Gowan 2012; Berntson and Marklund 2007). For instance, De Cuyper et al. (2014) observed that perceived employability is positively associated with subjective well-being at work. Also, Knabe and Rätzel (2011) have maintained that perceived employability is as vital as present employment status.

Following the theoretical distinction between wants and needs (Allardt 1993), and on the grounds of above-mentioned empirical evidence, we hypothesize that the perceptions of economic conditions matter for subjective well-being beyond individual income and employment (hypothesis 1).

While the effects of economic crises on subjective well-being have been researched extensively (De Neve et al. 2018; Dolan et al. 2008), ${ }^{1}$ fewer studies have examined the intersections between perceptions of economic conditions (consumer confidence in the economic literature), economic crises and subjective well-being. One example is Lemmon and Portniaguina (2006), who discovered that consumer confidence only predicted investor optimism indicators after the 1977 economic crisis due to the increase of household participation in stock markets. Other research demonstrated that rising stock prices have a positive relationship with consumer confidence as investors interpret it as a positive macroeconomic sign (Otoo 1999; Jansen and Nahuis 2003).

Another related example is Lolić et al. (2017), who have shown that the macroeconomic sentiment of the evolution of the national economy - a crucial psychological dimension

\footnotetext{
${ }^{1}$ De Neve et al. (2018) found that economic crises negatively affect individuals' life satisfaction twice as much than periods of economic growth.
} 
of consumer confidence-grows significantly during a macroeconomic crisis. Relatedly, Giugni and Mexi (2018) have observed that even if the 2008 recession had few measurable macroeconomic effects on Switzerland's economy, its citizens still experienced its deleterious effects in terms of negative perceptions of economic conditions.

The 2008 Economic Crisis is an example of an event with the capacity to trigger a high level of negative perceptions of economic conditions and decrease consumer confidence. Based on previous empirical evidence, we expect that the relationship between perceived economic conditions and subjective well-being will matter more during the period of the 2008 Economic Crisis than during the prosperous periods that preceded it (hypothesis 2). The expected differentiation of the effects by designated socioeconomic groups follows in the next section.

\subsection{The Role of Social Background}

Social cognitive theory signals the potential mediating role that social background, which encompasses social class, education and life experiences (Doney et al. 1999), can play in the relationship between perceived economic conditions, economic crises and subjective well-being. Individuals are ranked as belonging to low, middle or high social background on the basis of a combination of those elements. High social background implies a high level of income, economic security and ample opportunities for economic advancement, whereas low social background scores rather low on those dimensions (Connelly et al. 2016). Individuals with equivalent social backgrounds tend to be socialized similarly and develop specific social behaviours and social cognitive responses to everyday experiences (Fiske and Markus 2012). These behaviours are reinforced by everyday interactions that often take place in closed social circles. In this way, social background influences self-perceptions about individual positions and future expectations (Bandura 1999). Also, social pressures cause individuals to entertain different professional goals in accordance with their social background, and the within-group comparison surfaces (Becker et al. 2017; Pennington et al. 2016).

Different empirical studies have illustrated the postulates of social cognitive theory. Anderson et al. (2006) suggested that on average individual perceptions of status match perceptions of group status. Batruch et al. (2017) have shown that high achieving students from low social backgrounds usually feel less capable than their middle or high social background counterparts due to social pressures. Hoff and Priyanka (2005) demonstrated that, when caste is not publicly revealed, Indian children perform similarly in maze games. However, when caste is revealed, social pressure appears to cause children of lower castes to underperform. Similarly, sociological research on higher education shows that university students from low social backgrounds usually feel unwelcome or exhibit signs of impostor syndrome (Rubin 2012; Reay et al. 2010) and perceive themselves as less skilled than their high social background counterparts (Jury et al. 2017; Ivcevic and Kaufman 2013).

This theoretical framework and the related empirical research demonstrate the importance of the inclusion of social background in understanding why individuals could perceive and react differently to the same economic situation. A few researchers have previously put forth this argument, particularly in relation to the recent economic crisis. In an empirical study about perceptions of crisis across social classes in Germany, Kiess and Lahusen (2018) argued that citizens from the middle social class might be more affected by economic uncertainty during times of economic crisis than low and high social class citizens. Their research illustrated that this happens because, when compared to those of a 
lower social background, middle class individuals view themselves as having 'something to lose' (Kiess and Lahusen 2018: 190). Further, middle class individuals operate without the economic security of upper social background individuals. The authors thus speculated that middle social background individuals have more social expectations of status, efforts and goals than individuals from lower social backgrounds. When these expectations are not met (e.g. in times of crisis), the subjective well-being of these individuals will be more negatively affected in comparison to those with fewer expectations (low social background individuals) or with more resources (high social background individuals). The inability to fulfil these expectations has been known in the literature as 'status panic' (Bude 2017).

Similarly, Steijn et al. (1998) have argued that the middle class in the West, especially in Europe, is expected to suffer the most from economic downturns. From the 1980s, the growing flexibility of the labour market coupled with increasingly precarious working conditions and long-term unemployment have become part of the collective consciousness of large swathes of the middle class. These individuals have begun to feel that their economic and social position is threatened, and consequently their job security and career prospects. At the same time, these processes have been accompanied by the consolidation of individualistic values, based on an orientation toward achievement and a consumerist lifestyle. These factors have caused the middle class to feel the pressure of individual achievement and social expectations without the resource protection of high-class individuals, which has engendered a durable sense of anxiety. On the contrary, lower social background individuals tend to undervalue their actual knowledge, abilities and possibilities, and therefore develop lower expectations for social mobility due to within-group social pressure (Soria and Stebleton 2013; Ivcevic and Kaufman 2013). ${ }^{2}$

The above theoretical and empirical evidence provides a basis for the following two hypotheses: perceived economic conditions matter strongly for the subjective well-being of individuals from middle social backgrounds (hypothesis $3 a$ ), and perceptions of economic conditions in times of economic crisis will matter strongly for the subjective well-being of individuals of middle social background, and less strongly for those of low and high social backgrounds (hypothesis 3b).

\subsection{The Focus: Catalonia, Spain}

The three hypotheses are tested within different economic periods in Spain, more specifically the region of Catalonia. Spain is considered a well-developed European Union (EU) economy but it experienced one of the most negative socioeconomic fallouts from the Great Recession of 2008, particularly in comparison to other EU countries. Spain suffered the highest growth of inequality and unemployment in Europe resulting from the 2008 Economic Crisis (OECD 2016). From 2007 to 2012, the unemployment rate rose from 8.57 to $25.77 \%$, particularly affecting young people (from $18.1 \%$ for those aged 16 to 24 years old in 2007 to $52.9 \%$ in 2012) (Spanish Statistical Office 2020).

Catalonia has always been a wealthy region in Spain with a stable social structure. It closely mirrors the average Spanish unemployment rates before and after the 2008 Economic Crisis (Spanish Statistical Office 2020). For example, since the start of the

\footnotetext{
${ }^{2}$ Similar arguments were made by Bourdieu (1986) who suggested that lower social background individuals suffer from the social pressure of being less capable in comparison to others, hence impeding social mobility mechanisms.
} 
economic crisis, the unemployment rate in Catalonia was typically only $2 \%$ below that of Spain as a whole. Also, from 2002 to 2012 the percentage of newly-registered permanent labour contracts fluctuated between an average of $7 \%$ and $12 \%$ in both Catalonia and Spain (Statistical Institute of Catalonia 2020).

\section{Methodology}

\subsection{The Catalan PaD Dataset}

Catalonia is home to the only available longitudinal survey in Spain, the so-called 'Panel of Social Inequalities in Catalonia' $(\mathrm{PaD})$. This is a representative panel survey that collected information on individuals within Catalan households from 2001 to 2012. The panel consisted of 11 waves (2001-2012) that offer key information on socioeconomic conditions, equality, justice and subjective well-being. On average, the survey covered around 1760 individuals per wave ( $\mathrm{PaD} 2014)$, yet the panel faced substantial attrition over time (from 50 to $70 \%$ depending on additional sample groups). The final dataset for the purpose of this analysis comprises 10,451 individual yearly observations.

The consultation of panel data is an advantage for a study of perceived economic conditions and subjective well-being because of the high interdependence between previous, present and future values of all subjective measures, including the two main variables (Wooldridge 2001). Introducing the temporal dimension into the variables provides a better degree of evidence regarding the existence of causal relations (Finkel 1995) because issues of endogeneity (i.e. the correlation between the predictor variables and the error term of the regression) can be better handled.

\subsection{Empirical Model}

We developed the following equation to model the relationship between perceived economic conditions and subjective well-being according to a longitudinal perspective:

$$
S W_{i t}=\propto+\text { perceptions }_{i t} \psi+\text { ecrisis }_{t} \beta+\left[\text { perceptions } \times \text { ecrisis }_{i t}\right]+X_{i t} \delta+\varepsilon_{i t},
$$

where $S W$ denotes the subjective well-being of individual i in year $t$, perceptions represents the perception of economic conditions by individual $i$ in year $t$, ecrisis refers to economic conditions before and during the economic crisis (period dummies) and perceptions $\times$ ecrisis $_{i t}$ signifies the interaction between the perception of economic conditions by individual $i$ in year $t$ and the economic crisis. The vector $X_{i t}$ designates a set of individual time-varying characteristics such as age, educational attainment, income, marital status, individual labour market status and rural or urban area. Finally, $\varepsilon$ is the error term. This model is tested using the entire sample; subsequently, we split the sample into subgroups based on social or socioeconomic background following the Erikson-Goldthorpe-Portocarero framework (Martinez-Celorrio and Marin-Saldo 2010), with which we test the specific application of the general model. 


\subsection{Dependent and Independent Variables}

Subjective Well-Being Our dependent variable is self-reported well-being or, more precisely, 'satisfaction with life'. Diener et al. (1985) developed the 'Satisfaction with Life Scale', which became the standard measure of subjective well-being (Kahneman and Krueger 2006; Layard 2005). Psychological literature points out that this is a valid measure of true inner individual subjective well-being because individual answers are found to be correlated to inner psychological states. For example, Ekman et al. (1990) have argued that people with higher levels of subjective well-being tend to smile more. Similarly, Sutton and Davidson (1997) concluded that survey responses were highly correlated with electroencephalography and the prefrontal area of the brain, which is precisely the part responsible for reproducing the feeling of subjective well-being. Furthermore, Larsen and Eid (2008) have suggested that since individual welfare depends on experiences and cognitive judgments, self-examination is essential to the construction of an individual well-being metric.

The Satisfaction with Life Scale is usually included on representative population surveys, and is based on questions like the following: 'Taking all things into consideration, what is your level of satisfaction with life in general? Note that 0 is very dissatisfied and 10 is very satisfied'. This formulation has been adopted by the PaD survey we use, and the question appears in seven out of the 11 waves. Nonetheless, due to data availability for other variables, only five waves were used in the final sample: 2003, 2004, 2008, 2011 and 2012.

Perceptions of Economic Conditions This is our main independent variable, designated by two components: the perception of economic conditions of Catalan society as a whole and the perceptions of economic conditions of individual households. Therefore, we have combined two questions from the PaD survey: 'How do you perceive the economic position of the Catalan society next year in comparison with this year?' (perceptions_e); and 'How do you perceive the economic position of your household next year in comparison with this year?' (perceptions_h). The first question refers to the general economic situation and captures sentiments about macro conditions, while the second more closely reflects the understood situation for the household, that is, a micro dimension. This is in line with the above-mentioned definition of consumer confidence, which reflects both micro and macro sentiments. Both appear in all waves except the year 2010.

Individuals were able to choose between five options in the survey: conditions are much better (1), better (2), equal (3), worse (4) or much worse (5). To facilitate interpretation, we normalize the values from 0 to 1 , where 0 means much better and 1 means much worse. The combined variable provides equal weight to each question and is calculated as perceptions $=0.5 *$ perceptions_h $+0.5 *$ perceptions_e, where the same relative importance is given to each response category. We have performed additional robustness checks by changing the applied weights to the two perception-related components. In a first alternative, we have applied the weight of 0.67 to the perception of the economic position of the household, and the weight of 0.33 to the perception of the general societal economic position: perceptions $=0.67 *$ perceptions_h $+0.33 *$ perceptions_e. In a second alternative, we switch the weights between the components: perceptions $=0.33 *$ perceptions_h $+0.67 *$ perceptions_e. None of the alternative specifications significantly changed the size and the significance of the coefficient of the perception of economic circumstances in the models and its interaction with other variables. 
Thus, we present only the results of the combined indicator with equal weights, while the analyses resulting from alternatives are available upon request. Due to data availability in the whole sample, the variable was used in five waves.

Economic Crisis This variable represents the economic conditions in the present waves of the survey. It is coded from 0 to 1 in order to represent the years before the 2008 Economic Crisis and the years that followed (2009-2012). We have not included 2008 as a crisis year because the first effects of the crisis on the Spanish economy and society were reported in 2009 (Spanish Statistical Office 2020). Given the available waves, the variable takes a value of 1 in years 2011 and 2012 and 0 in years 2003, 2004 and 2008.

Social Background This variable has been categorized according to the father's social class within the Erikson-Goldthorpe-Portocarero framework (Martinez-Celorrio and Marin-Saldo 2010). It asks respondents to identify the occupational group of their father out of nine options: I (higher grade professionals, administrators and officials; managers in major industries; proprietors of large businesses); II (lower grade professionals, administrators and officials; higher grade technicians; managers in small industries; supervisors of non-manual labour employees); III (routine non-manual labour employees, both higher and lower grade); IV (small-scale proprietors; artisans; farmers and smallholders; other self-employed workers in primary production); V-VI (lower grade technicians; supervisors of manual labourers; skilled manual labourers); VIIa (semi-skilled or unskilled manual labourers); VIIb (agricultural workers). Following the suggestions of the Erikson-Goldthorpe-Portocarero framework, the respondents' social background is simplified into three main groups: low (VI and VII), middle (III, IV and V) and high (I and II).

\subsection{Control Variables}

We control for variables at the individual level that are shown to be relevant for subjective well-being. These are age, age squared, education, own net income, marital status, migrant status, labour market status, and urban or rural status. Following evidence of an inverse U-shaped relationship between income and well-being, we tested whether income squared fits in the final model. We found that the effect of income is better represented by the linear term only. Age is a continuous variable. Age squared is included due to empirical evidence that shows its U-shaped relationship with subjective well-being (Diener and Suh 1997; Clark and Oswald 2006). Education entails four levels: primary, secondary, post-secondary and tertiary education. The log of own net income is included in the analysis. Marital status includes single, married and divorced/separated/widow. Labour market situation is a four-category variable that demonstrates whether individuals work full-time, part-time, are inactive or unemployed. Rural or urban status is also a dummy variable, where 1 means the individual lives in a rural area and 0 means that the individual lives in an urban area.

\subsection{Sample}

The initial sample consisted of 30,456 observations. No restrictions were made on the age of the respondents or any other characteristic. The final sample size, however, dropped substantially due to missing values for some of the key independent variables, more precisely perceptions of economic conditions; 13,873 observations were deleted due to missing values on the variable measuring the economic perception of Catalan society, yet the missing values were fairly proportionally distributed across waves. A further 1222 observations were deleted due to missing information on perceptions of the economic position of the 
household, 496 observations were missing on the variable social origin, one observation was deleted due to the missing age and nine observations were excluded due to missing responses on education. The variable of net income was missing in 4121 cases, a substantial part of which came from the first wave. Moreover, two observations were excluded due to missing values on marital status and 238 observations because of missing values on the labour market status. Forty-three observations were missing an answer to the satisfaction variable. The final sample after considering all the missing values totalled 10,451 observations and included five waves.

\section{Results}

\subsection{Descriptive Statistics}

Table 1, descriptive statistics, is shown below. The average value of life satisfaction in the sample is 7.3 over the period studied. This is almost one point higher than the Spanish life satisfaction average for the same period and ranks in the world's highest reported levels of subjective well-being (World Happiness Report 2019). Catalonia is one of the most economically developed Spanish regions, a possible explanation for the difference in satisfaction. The mean value of perceptions of economic conditions is 0.56. Even if this value might suggest that in general Catalans have slightly negative perceptions, it might be more useful to compare the value of these perceptions during times of economic prosperity and crisis (Table 2). Regarding the other covariates, the sample shows that there is a balance between women (51\%) and men (49\%). The mean age value is 48 years old. Further, the sample shows that $35 \%$ of individuals come from rural areas, in contrast to the $65 \%$ living in cities. A substantial part of the respondents in our sample come from low and middle social backgrounds (48\% and $42 \%$ respectively) and $10 \%$ from high social background.

Table 2 depicts the mean values of life satisfaction and perceptions of economic conditions by individual social background.

In times of economic prosperity, life satisfaction for all groups amounts to an average of 7.53. The highest life satisfaction is found in the group of high social background individuals, though the difference between social groups is not profound. Middle and low social background individuals score similarly on average, and the difference between scores is not significant. In times of economic crisis, the levels of life satisfaction drop for all individuals, particularly those from high and low social backgrounds. However, high social background individuals still appear to hold the highest average life satisfaction, although the relative distance from the middle group declines and loses significance. In terms of perceptions of economic conditions, they worsen from times of prosperity to times of crisis. Also, group differences are rather minimal during times of prosperity, and they tend to remain rather low also in times of economic crisis, though at a lower level (drop of 0.1 on $0-1$ scale).

\subsection{Perceived Economic Conditions, Economic Crisis and Life Satisfaction}

In our analysis, we rely on fixed-effects models, in which only variations between individuals are considered (i.e. how a change in the independent variable relates to a change in the dependent one for the same person; Wooldridge 2002). The Haussmann test estimating fixed and random effects indicates that the models are systematically different, thus 
Table 1 Descriptive statistics (full sample)
Variables

Mean

(SD)

Life satisfaction

7.371

(1.582)

Perception of economic conditions

0.568

(0.174)

2008 Economic Crisis

0.444

(0.497)

Age

48.57

(16.66)

Men

0.486

(0.500)

Primary education

0.334

(0.472)

Secondary education

0.275

(0.447)

0.0902

(0.287)

0.301

(0.459)

6.989

(0.703)

0.632

(0.482)

0.249

(0.433)

0.118

(0.323)

0.586

(0.493)

0.0838

Part-time

(0.277)

0.0559

(0.230)

0.274

(0.446)

0.355

(0.478)

0.10

(0.30)

0.42

(0.49)

0.48

(0.50)

10,451

4497

Number of individuals 
Table 2 Descriptive statistics before and during the 2008 Economic Crisis by social background

\begin{tabular}{lllllll}
\hline Economic prosperity & & & & \multicolumn{2}{l}{2008 Economic Crisis } \\
\cline { 1 - 1 } Social background & Life satisfaction & Perceptions & & Life satisfaction & Perceptions \\
\hline All & 7.53 & 0.52 & & 7.17 & 0.62 \\
& $(1.38)$ & $(0.16)$ & & $(1.78)$ & $(0.17)$ \\
High & 7.74 & 0.51 & & 7.28 & 0.60 \\
& $(1.14)$ & $(0.15)$ & & $(1.67)$ & $(0.17)$ \\
Middle & 7.52 & 0.53 & & 7.21 & 0.62 \\
& $(1.32)$ & $(0.17)$ & & $(1.78)$ & $(0.17)$ \\
Low & 7.50 & 0.52 & & 7.10 & 0.63 \\
& $(1.46)$ & $(0.17)$ & & $(1.81)$ & $(0.17)$ \\
\hline
\end{tabular}

rejecting the null hypothesis of equality between the two. Therefore, the fixed-effects models are preferred for these analyses as they are more efficient (Allison 2009). As error terms might be auto correlated because errors of different years influence each other, we adjust for clustered standard errors.

Four models, presented in Table 3, are used to test our first two hypotheses. The first one, the empty model, only contains perceptions of economic conditions as the main independent variable. The second model introduces control variables at the individual level such as age, age squared, education, income, marital status, migrant status, labour market status and urban-rural distinction. The third model adds the role of the 2008 Economic Crisis, which is operationalised through an economic crisis dummy that groups waves relative to the crisis (before or during). Finally, the fourth model comprises the interaction between perceptions of economic conditions and the period of economic crisis. In other words, it demonstrates to what extent the economic crisis moderates the association between perceptions of economic conditions and life satisfaction. All models use the variable perceptions of economic conditions that combine, with equal weights, both micro and macro dimensions (i.e. one that refers to evaluation of the situation of the household and the other referring to society as a whole).

All the models show that negative perceptions (e.g. expecting that the next year will be worse than the previous one) are negatively correlated with life satisfaction. In model 3 , this relationship is found net of specific periods and the characteristics of individuals. The change in life satisfaction due to perceptions of economic conditions (ranging from better to worse) is -0.595 on a $0-10$ scale and has a size of about one-tenth of the standard deviation, which is a relatively high effect compared to other variables. The coefficients of perceptions in models 1,2 and 3 are statistically significant at $1 \%$. Hypothesis 1 stipulated that there is a relationship between perceived economic conditions and subjective well-being, net of individual objective economic conditions in terms of income and employment. Indeed, the results support the prediction that the relationship between perceptions of economic conditions and subjective well-being extends beyond the influence of the variables for individual income and labour market position. The sign and direction of control variables is mostly in line with results suggested in the current literature on subjective well-being. For instance, income is statistically significant and positively related to life satisfaction, together with having tertiary education. The exceptions are labour market situation variables, because being unemployed or inactive is positively correlated with 
Table 3 Perception of economic conditions and life satisfaction using ordinary least square (OLS) fixedeffects regressions

\begin{tabular}{|c|c|c|c|c|}
\hline Variables & Model 1 & Model 2 & Model 3 & Model 4 \\
\hline Perceptions of economic conditions & $\begin{array}{l}-0.934 * * * \\
(0.126)\end{array}$ & $\begin{array}{l}-0.516^{* * * *} \\
(0.135)\end{array}$ & $\begin{array}{l}-0.595 * * * \\
(0.135)\end{array}$ & $\begin{array}{l}-0.114 \\
(0.148)\end{array}$ \\
\hline 2008 Economic Crisis & & & $\begin{array}{l}-0.488 * * * \\
(0.052)\end{array}$ & $\begin{array}{l}0.135 \\
(0.154)\end{array}$ \\
\hline $\begin{array}{l}2008 \text { Economic Crisis\#perceptions of } \\
\text { economic conditions }\end{array}$ & & & & $\begin{array}{l}-0.988 * * * \\
(0.230)\end{array}$ \\
\hline Age & & $\begin{array}{l}-0.217 * * * \\
(0.022)\end{array}$ & $\begin{array}{l}-0.150 * * * \\
(0.023)\end{array}$ & $\begin{array}{l}-0.170^{* * * *} \\
(0.023)\end{array}$ \\
\hline Age squared & & $\begin{array}{l}0.002 * * * \\
(0.000)\end{array}$ & $\begin{array}{l}0.002 * * * \\
(0.000)\end{array}$ & $\begin{array}{l}0.002 * * * \\
(0.000)\end{array}$ \\
\hline Secondary education & & $\begin{array}{l}0.199 \\
(0.284)\end{array}$ & $\begin{array}{l}0.235 \\
(0.285)\end{array}$ & $\begin{array}{l}0.239 \\
(0.285)\end{array}$ \\
\hline Post-secondary non-tertiary & & $\begin{array}{l}1.193 \\
(0.777)\end{array}$ & $\begin{array}{l}1.246 \\
(0.764)\end{array}$ & $\begin{array}{l}1.264 * \\
(0.759)\end{array}$ \\
\hline Tertiary education & & $\begin{array}{l}0.652^{*} \\
(0.342)\end{array}$ & $\begin{array}{l}0.731 * * \\
(0.343)\end{array}$ & $\begin{array}{l}0.746^{* *} \\
(0.345)\end{array}$ \\
\hline Own net income (log) & & $\begin{array}{l}0.172 * * * \\
(0.062)\end{array}$ & $\begin{array}{l}0.124 * * \\
(0.062)\end{array}$ & $\begin{array}{l}0.120 * \\
(0.062)\end{array}$ \\
\hline Single & & $\begin{array}{l}-0.204 * \\
(0.118)\end{array}$ & $\begin{array}{l}-0.199 * \\
(0.117)\end{array}$ & $\begin{array}{l}-0.185 \\
(0.117)\end{array}$ \\
\hline Divorced/separated/widow & & $\begin{array}{l}-0.174 \\
(0.145)\end{array}$ & $\begin{array}{l}-0.179 \\
(0.144)\end{array}$ & $\begin{array}{l}-0.184 \\
(0.143)\end{array}$ \\
\hline Part-time & & $\begin{array}{l}0.130 \\
(0.094)\end{array}$ & $\begin{array}{l}0.137 \\
(0.093)\end{array}$ & $\begin{array}{l}0.141 \\
(0.093)\end{array}$ \\
\hline Unemployed & & $\begin{array}{l}0.341 * * * \\
(0.111)\end{array}$ & $\begin{array}{l}0.368 * * * \\
(0.111)\end{array}$ & $\begin{array}{l}0.362 * * * \\
(0.112)\end{array}$ \\
\hline Inactive & & $\begin{array}{l}0.225 * * \\
(0.099)\end{array}$ & $\begin{array}{l}0.230 * * \\
(0.100)\end{array}$ & $\begin{array}{l}0.238 * * \\
(0.099)\end{array}$ \\
\hline Rural & & $\begin{array}{l}-0.222^{*} \\
(0.119)\end{array}$ & $\begin{array}{l}-0.167 \\
(0.119)\end{array}$ & $\begin{array}{l}-0.189 \\
(0.119)\end{array}$ \\
\hline Observations & 10,451 & 10,451 & 10,451 & 10,451 \\
\hline R-squared & 0.010 & 0.036 & 0.044 & 0.047 \\
\hline Number of individuals & 4497 & 4497 & 4497 & 4497 \\
\hline
\end{tabular}

Robust standard errors in parentheses

$* * * p<0.01 ; * * p<0.05 ; * p<0.1$

life satisfaction with respect to full-time employment, which is contrary to some of the evidence.

Model 4 demonstrates the effect of perception as a reaction to times of economic crisis in comparison to times of economic prosperity. The interaction effect amounts to -0.988 , demonstrating that negative perceptions of economic circumstances in times of crisis decrease individual life satisfaction by almost one point. Figure 1 illustrates this 


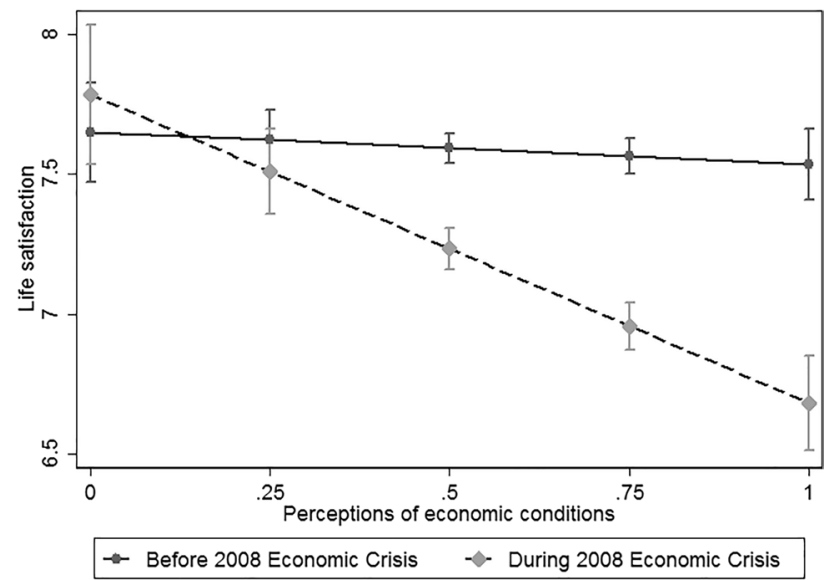

Fig. 1 Life satisfaction in relation to perceptions of economic conditions ( $0-1$; better to worse) before and during the 2008 Economic Crisis (predicted values)

relationship by depicting the extent to which economic crisis moderates the original relationship between perception and life satisfaction. As perceptions worsen in times of economic crisis, life satisfaction drops almost one point on the Likert scale (0-10). In contrast, in times of economic prosperity, life satisfaction is rather stable even when opinions worsen. Hypothesis 2 predicted that the relationship between perceived economic conditions and subjective well-being will matter more during the period of the 2008 Economic Crisis than during the prosperous periods that preceded it. The results indeed show that individuals' perceptions of economic conditions were negatively impacted as a result of the 2008 Economic Crisis.

\subsection{Perceived Economic Conditions and Social Background}

In order to test hypothesis 3, we regress the previous models, dividing the sample by social background. Social background can be considered a time-constant variable that only varies between individuals. Six models are presented in Table 4: models 1a and 2a concern individuals from high social backgrounds; models $1 \mathrm{~b}$ and $2 \mathrm{~b}$ encompass individuals from middle social backgrounds; models $1 \mathrm{c}$ and $2 \mathrm{c}$ represent individuals from low social backgrounds. All the sub-models contain major control variables as presented in model 3, Table 3. The difference between models 1 and 2 in Table 4 is that the latter includes the interaction between perceptions of economic conditions and the period of economic crisis.

Table 4 (models $1 \mathrm{a}, \mathrm{b}$ and $\mathrm{c}$ ) shows that whereas perceived economic conditions is strongly correlated with life satisfaction for individuals from middle and low social backgrounds, this relationship is weak and insignificant for individuals from high social backgrounds. Moreover, a somewhat strong relationship to life satisfaction appears for individuals from middle social backgrounds (coefficient of -0.695 , significant at $1 \%$ ), while it is less strong for individuals from low social backgrounds (the coefficient of -0.531 , at $5 \%$ significance).

Regarding the reaction to objective economic conditions, the perceptions of individuals from middle and low social background are affected by the 2008 Economic Crisis. For 
Table 4 Life satisfaction and perception of economic conditions by social background using ordinary least square (OLS) fixed-effects regressions

\begin{tabular}{|c|c|c|c|c|c|c|}
\hline \multirow[t]{2}{*}{ Variables } & \multicolumn{2}{|l|}{ High level } & \multicolumn{2}{|l|}{ Middle level } & \multicolumn{2}{|l|}{ Low level } \\
\hline & Model 1a & Model 2a & Model 1b & Model 2b & Model 1c & Model 2c \\
\hline \multirow{2}{*}{$\begin{array}{l}\text { Perceptions of economic } \\
\text { conditions }\end{array}$} & -0.536 & 0.039 & $-0.695 * * *$ & -0.133 & $-0.531 * *$ & -0.145 \\
\hline & $(0.442)$ & $(0.409)$ & $(0.192)$ & $(0.229)$ & $(0.209)$ & $(0.218)$ \\
\hline \multirow[t]{2}{*}{2008 Economic Crisis } & $-0.319 * *$ & 0.354 & $-0.353 * * *$ & $0.361^{*}$ & $-0.652 * * *$ & -0.131 \\
\hline & $(0.137)$ & $(0.439)$ & $(0.079)$ & $(0.219)$ & $(0.079)$ & $(0.244)$ \\
\hline \multirow{2}{*}{$\begin{array}{l}2008 \text { Economic } \\
\text { Crisis\#perceptions }\end{array}$} & & -1.119 & & $-1.129 * * *$ & & $-0.820 * *$ \\
\hline & & $(0.702)$ & & $(0.325)$ & & $(0.362)$ \\
\hline \multirow[t]{2}{*}{ Age } & $0.213 * * *$ & $0.235 * * *$ & $-0.183 * * *$ & $-0.205^{* * *}$ & $-0.118^{* * *}$ & $-0.137 * * *$ \\
\hline & $(0.073)$ & $(0.075)$ & $(0.033)$ & $(0.033)$ & $(0.034)$ & $(0.035)$ \\
\hline \multirow[t]{2}{*}{ Age squared } & $0.002 * *$ & $0.002 * * *$ & $0.002 * * *$ & $0.002 * * *$ & $0.002 * * *$ & $0.002^{* * * *}$ \\
\hline & $(0.001)$ & $(0.001)$ & $(0.000)$ & $(0.000)$ & $(0.000)$ & $(0.000)$ \\
\hline \multirow[t]{2}{*}{ Secondary education } & 0.453 & 0.486 & $-0.640^{*}$ & $-0.656^{*}$ & $1.084 * *$ & $1.100 * * *$ \\
\hline & $(0.526)$ & $(0.554)$ & $(0.381)$ & $(0.386)$ & $(0.432)$ & $(0.427)$ \\
\hline \multirow[t]{2}{*}{ Post-secondary non-tertiary } & $5.540 * * *$ & $5.652 * * *$ & -0.781 & -0.775 & $1.827^{*}$ & $1.849 * *$ \\
\hline & $(0.742)$ & $(0.753)$ & $(0.732)$ & $(0.735)$ & $(0.952)$ & $(0.931)$ \\
\hline \multirow[t]{2}{*}{ Tertiary education } & $1.455^{*}$ & 1.405 & -0.497 & -0.485 & $1.641 * * *$ & $1.674 * * *$ \\
\hline & $(0.817)$ & $(0.860)$ & $(0.522)$ & $(0.526)$ & $(0.439)$ & $(0.433)$ \\
\hline \multirow[t]{2}{*}{ Net own income $(\log )$} & $0.389^{*}$ & $0.373^{*}$ & $0.242 * * *$ & $0.242 * * *$ & -0.027 & -0.032 \\
\hline & $(0.201)$ & $(0.201)$ & $(0.083)$ & $(0.083)$ & $(0.096)$ & $(0.095)$ \\
\hline \multirow[t]{2}{*}{ Single } & -0.281 & -0.275 & 0.003 & 0.033 & $-0.413 * *$ & $-0.415^{* *}$ \\
\hline & $(0.264)$ & $(0.264)$ & $(0.162)$ & $(0.163)$ & $(0.199)$ & $(0.199)$ \\
\hline \multirow[t]{2}{*}{ Divorced/separated/widow } & 0.467 & 0.453 & -0.181 & -0.171 & $-0.322^{*}$ & $-0.333^{*}$ \\
\hline & $(0.398)$ & $(0.404)$ & $(0.247)$ & $(0.244)$ & $(0.188)$ & $(0.188)$ \\
\hline \multirow[t]{2}{*}{ Part-time } & 0.385 & 0.403 & 0.095 & 0.101 & 0.143 & 0.142 \\
\hline & $(0.295)$ & $(0.294)$ & $(0.144)$ & $(0.143)$ & $(0.133)$ & $(0.133)$ \\
\hline \multirow[t]{2}{*}{ Unemployed } & 0.420 & 0.423 & 0.208 & 0.205 & $0.465 * * *$ & $0.457 * * *$ \\
\hline & $(0.404)$ & $(0.405)$ & $(0.157)$ & $(0.157)$ & $(0.162)$ & $(0.163)$ \\
\hline \multirow[t]{2}{*}{ Inactive } & 0.102 & 0.117 & 0.210 & 0.207 & 0.252 & $0.266^{*}$ \\
\hline & $(0.311)$ & $(0.308)$ & $(0.134)$ & $(0.134)$ & $(0.160)$ & $(0.159)$ \\
\hline \multirow[t]{2}{*}{ Rural } & -0.165 & -0.291 & $-0.454 * *$ & $-0.465^{* * *}$ & 0.117 & 0.097 \\
\hline & $(0.675)$ & $(0.684)$ & $(0.176)$ & $(0.174)$ & $(0.159)$ & $(0.159)$ \\
\hline Observations & 1078 & 1078 & 4383 & 4383 & 4990 & 4990 \\
\hline R-squared & 0.076 & 0.080 & 0.051 & 0.055 & 0.047 & 0.049 \\
\hline Number of individuals & 481 & 481 & 1813 & 1813 & 2203 & 2203 \\
\hline
\end{tabular}

Robust standard errors in parentheses

$* * * p<0.01 ; * * p<0.05 ; * p<0.1$

those from a low social background, the value of the coefficient is -0.820 (significant at $5 \%$ ), whereas for individuals from a middle social background the interaction effect is 

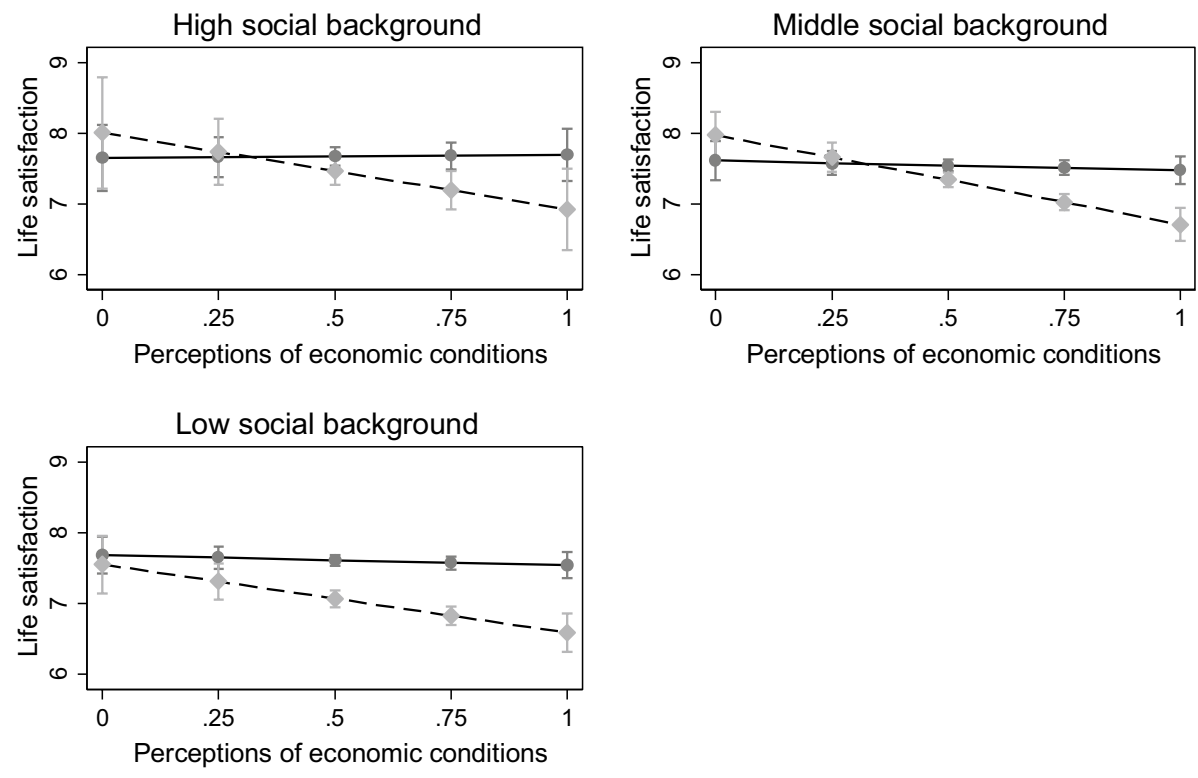

Before 2008 Economic Crisis

- - - During 2008 Economic Crisis

Fig. 2 Life satisfaction in relation to perceptions of economic conditions ( $0-1$; better to worse) before and during the economic crisis. Predicted values for individuals of high, middle and low social backgrounds

-1.129 (significant at $1 \%$ ). The interaction effects are not found for high social background individuals.

The results presented in Fig. 2 below offer further evidence by explicitly illustrating life satisfaction in relation to perceptions of economic conditions before and during the economic crisis for all groups. There are no statistically significant differences in life satisfaction between times of prosperity and crisis for high social background individuals at any level of perception of economic conditions. As an example, individuals with 0.5 level of perceived economic conditions will have similar life satisfaction both in times of prosperity and crisis. On the contrary, the higher the negative perception of economic conditions, the higher the gap in life satisfaction between periods of economic crisis and prosperity for individuals of low and middle social backgrounds. Above all, our results show that the perceptions of economic conditions in relation to economic crisis and life satisfaction are stratified by social background.

These findings are thus partly in line with the theoretical and empirical findings presented in previous sections. Specifically, there is basis to confirm our hypotheses $3 \mathrm{a}$ and $3 b$, which predicted that perceived economic conditions matter strongly for the subjective well-being of individuals from middle social backgrounds (hypothesis 3a); and perceptions of economic conditions in times of economic crisis matter strongly for the subjective well-being of individuals from middle social backgrounds, and less strongly for those of low and high social backgrounds (hypothesis $3 b$ ).

However, our findings also indicate the similarity between middle and low social background individuals, suggesting that an economic crisis also greatly influences how perceived economic conditions affect the life satisfaction of low social background individuals. In contrast, our expectation is confirmed that perceptions of economic conditions 
among high social background individuals are only weakly associated with life satisfaction, also in times of economic crisis.

\section{Discussion and Conclusion}

This article studied the relationship between perceptions of economic conditions and subjective well-being in times of economic crisis and prosperity. It also analysed how this relationship plays out across different social backgrounds. Using panel survey data in the region of Catalonia, Spain, three findings emerge: (1) perceptions of economic conditions have an independent effect on subjective well-being beyond objective individual conditions such as income or employment; (2) these perceptions serve as a more relevant determinant of subjective well-being during periods of economic crisis; and (3) whereas there is a close link between perceptions of economic conditions and subjective well-being in the group of individuals from middle and low social backgrounds, the link is weak in the group of individuals from high social backgrounds. Therefore, our study provides further empirical evidence of social cognitive theory.

These results point to the importance of relying on individual perceptions when measuring the subjective well-being of individuals, and particularly for the case of Catalonia, Spain. Objective individual conditions were not sufficient to fully explain how individuals felt about their life in general. The 2008 Economic Crisis triggered changes in perceptions that went beyond the pecuniary effects of the 2008 Great Recession on people's subjective well-being. The analyses clearly show these patterns and suggest that policies need to consider people's perceptions when forecasting economic recoveries and people's well-being.

Moreover, it is important to consider the diversity of citizens in terms of their social background regarding how their perceptions influence individual well-being and react in times of downturns. The perceptions of individuals from middle social backgrounds particularly influence their sense of well-being and their response to downturns. A probable explanation is that they overestimate the possibility of social mobility during times of economic expansion. These expectations often translate into higher individual private debts, leading to a drastic drop in their perceptions of economic conditions during an economic downturn. This is in line with the related theoretical and empirical research described above (Kiess and Lahusen 2018; Bude 2017; Steijn et al. 1998).

Perceptions of economic conditions among high social background individuals are rather stable in terms of subjective well-being and not profoundly influenced by shifts in economic conditions. A potential explanation could be that they are much more protected in terms of resources and connections than other social groups (Kiess and Lahusen 2018). The results regarding low social background individuals are, however, rather surprising. Contrary to our initial expectations that perceptions of economic conditions for low social background individuals would be stable over time, our results show the existence of a strong relationship between perceptions of economic conditions and subjective well-being in times of economic prosperity, and an even stronger relationship in times of economic crisis. These results contradict related theoretical and empirical studies that state that individuals from low social backgrounds develop low expectations of social mobility due to their within and between-social group pressures (Soria and Stebleton 2013; Ivcevic and Kaufman 2013). At the same time, they empirically prove the claims that stem from social cognitive theory, reinforcing the view that social background influences the relationship between perceived economic conditions, economic crisis and subjective well-being. 
There are several potential explanations for these results. One possibility is the difficulty in distinguishing between low and middle social background individuals in changing socioeconomic settings, who might appear more or less distant from one another depending on the adopted classification. Different operationalisations (e.g. one or more dimensions, categorical or continuous variable) might have implications for the outcomes of interest (Meraviglia et al. 2016). In addition, related research points to the decline of the middle class in Western societies over the last 3 decades (Milanovic 2016), blurring the distinction between those from low and middle social backgrounds. For this reason, it is possible that social background no longer captures the differences for which it was initially created (Weeden and Grusky 2005).

Finally, specificities of the context in which the study is situated could also affect our results. For instance, during the construction boom and housing bubble that occurred in Spain in the 2000s, low social background individuals, especially those with low educational attainment working in construction-related jobs, earned a relatively high salary in comparison with someone of an average middle social background with higher qualifications, like teachers or office workers (Verges-Escuin 2014). This situation could have produced false expectations, and the positive feeling of 'social mobility' for these individuals and their relatives and friends. Their self-perception may have indicated they were of middle social background status. Hence, they developed similar psychosocial mechanisms.

Lastly, we acknowledge that the results of this article are subject to some limitations, which at the same time offer new avenues for research. For instance, even though it was argued that the objective macroeconomic conditions of Catalonia resemble those of Spain, some differences still exist. For example, Catalonia has always been one of the most economically developed regions in Spain. Other Spanish regions experienced more severe consequences from the 2008 Economic Crisis, and we would expect even stronger effects if our hypotheses were tested throughout Spain. More research would be needed to distinguish between uncertainty, risk and confidence, and their comparable role in subjective well-being. Another interesting extension would be to apply the examination proposed in this study to other national panel datasets that contain information on both economic prosperity and economic crisis periods, ideally with less attrition than ours (e.g. British, German or Swiss household panel datasets).

To conclude, this study contributes to the literature on economic and social psychology by providing further empirical evidence of how psychological biases influence subjective wellbeing. The results further add to previous sociological studies by providing new evidence about the psychosocial biases that exist among groups from different social backgrounds, influencing on their individual expectations, goals and efforts, as well as their level of subjective well-being. The research notes that perceptions of economic conditions matter for subjective well-being beyond labour market factors as well as other objective conditions. Thus, policymakers should take them into consideration when designing, implementing and examining policies that aim to increase individual welfare. This is especially relevant for the current COVID-19 pandemic which poses an unprecedented threat for the world population and has created different forms of risks and uncertainties, particularly economic ones. In line with this study, incorporating individual perceptions in major policy responses during the pandemic may be fundamental for citizens' well-being.

Acknowledgements The authors are grateful to the two anonymous referees for their very helpful comments on an earlier draft of this article. 


\section{References}

Allardt, E. (1993). Having, loving, being: An alternative to the Swedish model of welfare research. In N. Nussbaum \& A. Sen (Eds.), The quality of life (pp. 88-95). Oxford: Oxford University Press. https:// doi.org/10.1093/0198287976.003.0008.

Allison, P. D. (2009). Fixed effects regression models. Thousand Oaks: SAGE Publications.

Andersen, S. (2008). The short- and long- term effects of government training on subjective well-being. European Sociological Review, 24(4), 451-462.

Anderson, C., Srivastava, S., Beer, J., Spataro, S. E., \& Chatman, J. A. (2006). Knowing your place: Self-perceptions of status in social groups. Journal of Personality and Social Psychology, 91, 1094-1110.

Bandura, A. (1999). Social cognitive theory: An agentic perspective. Asian Journal of Social Psychology, 2, 22-41.

Batruch, A., Autin, F., \& Butera, F. (2017). Re-establishing the social order: Restorative reactions against high-achieving low social class pupils. Journal of Social Issue, 73(1), 42-60.

Becker, J. C., Kraus, M. W., \& Rheinschmidt-Same, M. (2017). Cultural expressions of social class and their implications for group-related beliefs and behaviors. Journal of Social Issues, 73(1), 158-174.

Berntson, E., \& Marklund, S. (2007). The relationship between perceived employability and subsequent health. Work \& Stress, 21(3), 279-292.

Borra, C., \& Gómez-García, F. (2016). Well-being at work and the great recession: The effect of others' unemployment. Journal of Happiness Studies, 17(5), 1939-1962.

Bourdieu, P. (1986). the forms of capital. In J. G. Richardson (Ed.), Handbook of theory and research for the sociology of education. New York: Greenwood Press.

Bovi, M. (2009). Economic versus psychological forecasting. Evidence from consumer confidence surveys. Journal of Economic Psychology, 30(4), 563-574.

Bude, H. (2017). Society of fear. New York: Wiley.

Burchell, B. (2011). A temporal comparison of the effects of unemployment and job insecurity on wellbeing. Sociological Research Online, 16(1), 1-13.

Campara, J. P., Vieira, K. M., \& Potrich, A. C. G. (2017). Overall life satisfaction and financial wellbeing: Revealing the perceptions of the beneficiaries of the Bolsa Familia Program. Revista de Administração Pública, 51(2), 182-200.

Chung, H., \& Mau, S. (2014). Subjective Insecurity and the role of institutions. Journal of European Social Policy, 24(4), 303-318.

Clark, A. E., \& Oswald, A. J. (2006). The curved relationship between subjective well-being and age. Milwaukee: HAL.

Connelly, R., Gayle, V., \& Lambert, P. S. (2016). A review of occupation-based social classifications for social survey research. Methodological Innovations, 9, 2059799116638003.

De Cuyper, N., Vanhercke, D., Peeters, E., \& De Witte, H. (2014). Defining perceived employability: A psychological approach. Personnel Review, 43(4), 592-605.

De Neve, J. E., Ward, G., De Keulenaer, F., Van Landeghem, B., Kavetsos, G., \& Norton, M. I. (2018). The asymmetric experience of positive and negative economic growth: Global evidence using subjective well-being data. Review of Economics and Statistics, 100(2), 362-375.

Diener, E., Emmons, R., Larsen, R., \& Griffin, S. (1985). The satisfaction with life scale. Journal of Personality Assessment, 49, 71-75.

Diener, E. D., \& Suh, M. E. (1997). Subjective well-being and age: An international analysis. Annual Review of Gerontology and Geriatrics, 17(1), 304-324.

Dolan, P., Peasgood, T., \& White, M. (2008). Do we really know what makes us happy? A review of the economic literature on the factors associated with subjective well-being. Journal of Economic Psychology, 29(1), 94-122.

Doney, P. M., Locke, E. A., Noorderhaven, N. G., Cannon, J. P., \& Mullen, M. R. (1999). Some reservations about social capital. Academy of Management Review, 24(1), 8-11.

Easterlin, R. A. (1974). Does economic growth improve the human lot? Some empirical evidence. In P. A. David \& M. W. Reder (Eds.), Nations and households in economic growth (pp. 89-125). New York: Academic Press.

Ekman, P., Davidson, R. J., \& Friesen, W. V. (1990). The Duchenne smile: Emotional expression and brain physiology: II. Journal of Personality and Social Psychology, 58(2), 342.

Finkel, S. E. (1995). Causal analysis with panel data. Thousand Oaks, CA.: Sage Publications.

Fisher, K. L., \& Statman, M. (2000). Investor sentiment and stock returns. Financial Analysts Journal, 56(2), 16-23. https://doi.org/10.2469/faj.v56.n2.2340. 
Fiske, S. T., \& Markus, H. R. (Eds.). (2012). Facing social class: How societal rank influences interaction. New York: Russell Sage Foundation.

Geishecker, I. (2012). Simultaneity bias in the analysis of perceived job insecurity and subjective wellbeing. Economics Letters, 116(3), 319-321.

Giugni, M., \& Mexi, M. M. (2018). The silent crisis: Perceptions and experiences of the economic crisis in Switzerland. In M. Grasso (Ed.), M Giugni. Cham: Citizens and the crisis. Palgrave studies in European political sociology. Palgrave Macmillan.

Green, F. (2011). Unpacking the misery multiplier: How employability modifies the impacts of unemployment and job insecurity on life satisfaction and mental health. Journal of Health Economics, 30(2), $265-276$.

Hacker, J. (2018). Economic security. In J. E. Stiglitz, J.-P. Fitoussi, \& M. Durand (Eds.), For good measure: Advancing research on well-being metrics beyond GDP. Paris: OECD Publishing.

Helliwell, J., Layard, R., \& Sachs, J. (2019). World happiness report 2019. New York: Sustainable Development Solutions Network.

Hoff, K., \& Priyanka, K. (2005). Belief systems and durable inequalities: An experimental investigation of Indian caste. World bank policy research working paper, 3351.

Ivcevic, Z., \& Kaufman, J. C. (2013). The can and cannot do attitude: How self-estimates of ability vary across ethnic and socioeconomic groups. Learning and Individual Differences, 27, 144-148.

Jansen, W. J., \& Nahuis, N. J. (2003). The stock market and consumer confidence: European evidence. Economics Letters, 79(1), 89-98.

Jury, M., Smeding, A., Stephens, N. M., Nelson, J. E., Aelenei, C., \& Darnon, C. (2017). The experience of low-SES students in higher education: Psychological barriers to success and interventions to reduce social-class inequality. Journal of Social Issues, 73(1), 23-41.

Kahneman, D., \& Krueger, A. (2006). Developments in the measurement of subjective well-being. Journal of Economic Perspectives, 20(1), 3-24.

Karren, R., \& Gowan, M. A. (2012). Employability, well-being and job satisfaction following a job loss. Journal of Managerial Psychology, 27, 772-779.

Kiess, J., \& Lahusen, C. (2018). An island of bliss-For everyone? Perceptions and experiences of the crisis across social classes in Germany. In M. Grasso \& M. Giugni (Eds.), Citizens and the crisis (pp. 189-214). Cham: Palgrave Macmillan.

Knabe, A., \& Rätzel, S. (2011). Quantifying the psychological costs of unemployment: The role of permanent income. Applied Economics, 43(21), 2751-2763.

Knight, F. H. (1921). Risk, uncertainty and profit. Chicago: University of Chicago Press.

Krause, N., Jay, G., \& Liang, J. (1991). Financial strain and psychological well-being among the American and Japanese elderly. Psychology and Aging, 6(2), 170.

Larsen, R. J., \& Eid, M. (2008). Ed Diener and the science of subjective well-being. In M. Eid \& R. J. Larsen (Eds.), The science of subjective well-being (pp. 1-13). New York: The Guilford Press.

Layard, R. (2005). Happiness. London: Allen Lane.

Layard, R. (2010). Measuring subjective well-being. Science, 327(5965), 534-535.

Lemmon, M., \& Portniaguina, E. (2006). Consumer confidence and asset prices: Some empirical evidence. The Review of Financial Studies, 19(4), 1499-1529.

Lolić, I., Sorić, P., \& Čižmešija, M. (2017). Personal finances vs the overall economic conditions: What drives the new EU member states' stock markets? Comparative Economic Research, 20(4), 125-142.

Luechinger, S., Meier, S., \& Stutzer, A. (2010). Why does unemployment hurt the employed? Evidence from the life satisfaction gap between the public and the private sector. Journal of Human Resources, 45(4), 998-1045.

Martinez-Celorrio, X., \& Marin-Saldo, A. (2010). Educació i ascens social a Catalunya. Fundació Jaume Bofill.

Meraviglia, C., Ganzeboom, H. B., \& De Luca, D. (2016). A new international measure of social stratification. Contemporary Social Science, 11(2-3), 125-153.

Merkle, D. M., Langer, G. E., \& Sussman, D. (2003). Consumer confidence: Measurement and meaning. In Conference of the American Association for Public Opinion Research.

Milanovic, B. (2016). Global inequality: A new approach for the age of globalization. Cambridge: Harvard University Press.

OECD. (2016). OECD employment outlook 2016. Paris: OECD Publishing. https://doi.org/10.1787/empl_ outlook-2016-en.

Oskrochi, G., Bani-Mustafa, A., \& Oskrochi, Y. (2018). Factors affecting psychological well-being: Evidence from two nationally representative surveys. PloS One, 13(6), e0198638.

Otis, N. (2017). Subjective well-being in China: Associations with absolute, relative, and perceived economic circumstances. Social Indicators Research, 132(2), 885-905. 
Otoo, M. W. (1999). Consumer sentiment and the stock market. FEDS working paper no. 99-60. Available at SSRN: https://ssrn.com/abstract=205028. https://doi.org/10.2139/ssrn.205028. Accessed 05 June 2020.

Panel de Desigualtats de Catalunya (PaD). (2014). Retrieved March 2, 2020, from https://www.fbofill.cat/ plana-basica/lenquesta.

Pennington, C. R., Heim, D., Levy, A. R., \& Larkin, D. T. (2016). Twenty years of stereotype threat research: A review of psychological mediators. PLoS ONE, 11(1), e0146487.

Reay, D., Crozier, G., \& Clayton, J. (2010). "Fitting in" or "standing out": Working-class students in UK higher education. British Educational Research Journal, 36(1), 107-124.

Rocha, C., \& Strand, E. B. (2004). The effects of economic policies and employment assistance programs on the well-being of displaced female apparel workers. Journal of Family Issues, 25(4), 542-566.

Rubin, M. (2012). Social class differences in social integration among students in higher education: A metaanalysis and recommendations for future research. Journal of Diversity in Higher Education, 5(1), 22-38.

Runde, J. (1998). Clarifying Frank Knight's discussion of the meaning of risk and uncertainty. Cambridge Journal of Economics, 22(5), 539-546.

Sen, A. (2009). The idea of justice. London: Allen Lane.

Soria, K. M., \& Stebleton, M. J. (2013). Social capital, academic engagement, and sense of belonging among working-class college students. College Student Affairs Journal, 31(2), 139-153.

Spanish Statistical Office. (2020). Economic activity, employment and unemployment, 2019. Retrieved March 2, 2020, from https://www.ine.es/dyngs/INEbase/en/categoria.htm?c=Estadistic a_P\&cid=1254735976594.

Statistical Institute of Catalonia. (2020). Labour, 2019. Retrieved March 2, 2020, from https://www.idesc at.cat/tema/treba?lang=en.

Steijn, B., Berting, J., \& de Jong, M. J. (Eds.). (1998). Economic restructuring and the growing uncertainty of the middle class. Berlin: Springer.

Stiglitz, J., Fitoussi, J., \& Durand, M. (2018). Beyond GDP: Measuring what counts for economic and social performance. Paris: OECD Publishing. https://doi.org/10.1787/9789264307292-en.

Strandh, M. (2001). State intervention and mental well-being among the unemployed. Journal of Social Policy, 30(1), 57-80.

Sutton, K., \& Davidson, R. (1997). Prefrontal brain asymmetry: A biological substrate of the behavioural approach and inhibition systems. Psychological Science, 8, 204-210.

Tonzer, L. (2017). Uncertainty, financial crises, and subjective well-being. IWH discussion papers, 2/2017.

Van Praag, B. M., Frijters, P., \& Ferrer-i-Carbonell, A. (2003). The anatomy of subjective well-being. Journal of Economic Behavior \& Organization, 51(1), 29-49.

Verges-Escuin, R. (2014). España: del sueño de un bienestar económico a la realidad de un endeudamiento masivo. Observatorio inmobiliario y de la construcción, 69, 67-71.

Weeden, K. A., \& Grusky, D. B. (2005). The case for a new class map. American Journal of Sociology, $111(1), 141-212$.

Wooldridge, J. M. (2001). Introductory econometrics: A modern approach (Spanish translation). Stamford: Thomson.

Wooldridge, J. M. (2002). Econometric analysis for cross-section and panel data. Cambridge: MIT Press.

Publisher's Note Springer Nature remains neutral with regard to jurisdictional claims in published maps and institutional affiliations. 